University of South Florida

DIGITAL COMMONS

@ UNIVERSITY OF SOUTH FLORIDA
Digital Commons @ University of

South Florida

$9-1-2002$

\title{
Volusia County Transportation Disadvantaged Service Plan
}

CUTR

Follow this and additional works at: https://digitalcommons.usf.edu/cutr_nctr

\section{Scholar Commons Citation}

CUTR, "Volusia County Transportation Disadvantaged Service Plan" (2002). Research Reports. 224.

https://digitalcommons.usf.edu/cutr_nctr/224

This Technical Report is brought to you for free and open access by the National Center for Transit Research (NCTR) Archive (2000-2020) at Digital Commons @ University of South Florida. It has been accepted for inclusion in Research Reports by an authorized administrator of Digital Commons @ University of South Florida. For more information, please contact digitalcommons@usf.edu. 


\title{
VOLUSIA COUNTY TRANSPORTATION DISADVANTAGED SERVICE PLAN
}

\author{
September 2002
}

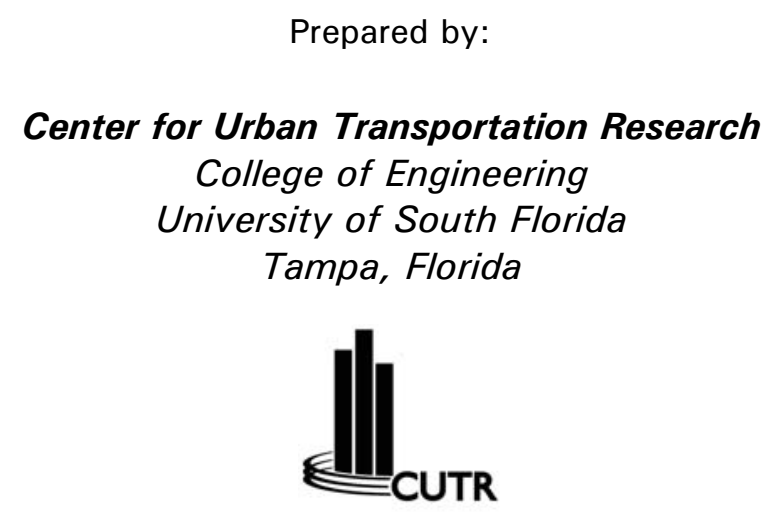





\section{TABLE OF CONTENTS}

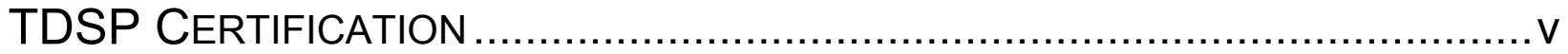

ROLL CALL VOTE ON TDSP ............................................................ vii

\section{DeVelopment Plan}

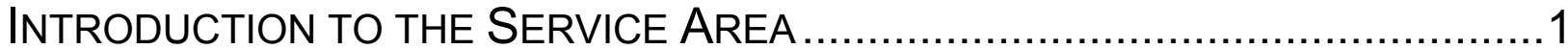

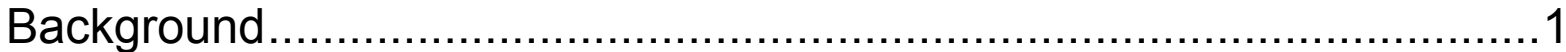

Consistency Review of Other Plans ............................................... 3

Local Coordinating Board Certification ..............................................

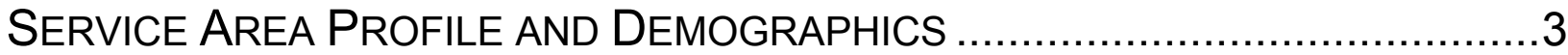

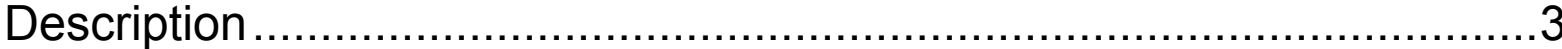

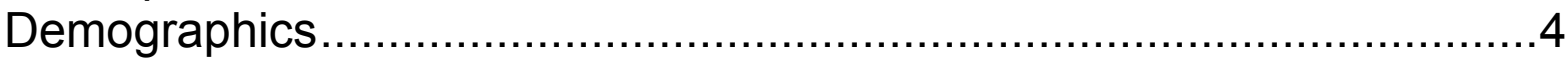

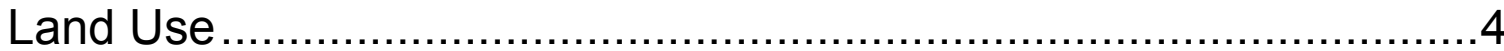

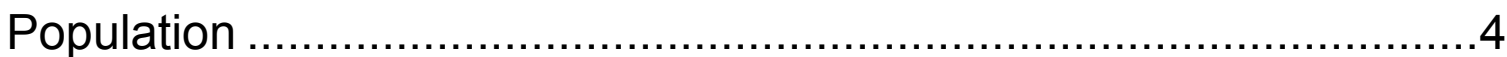

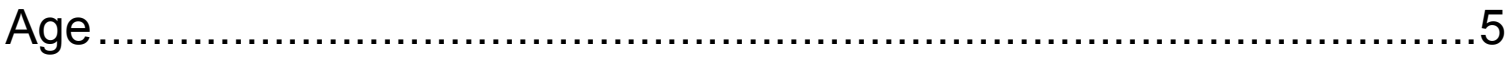

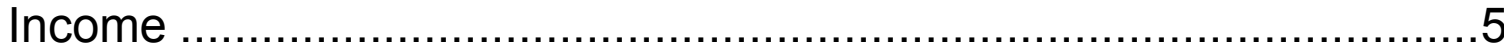

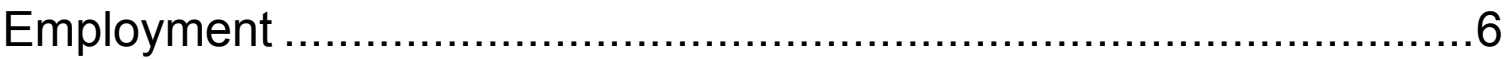

Major Paratransit Trip Generators ............................................

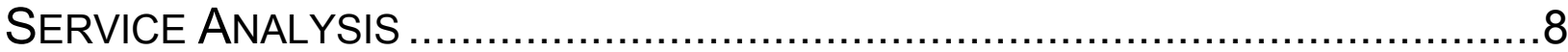

Forecasts of TD Population ........................................................

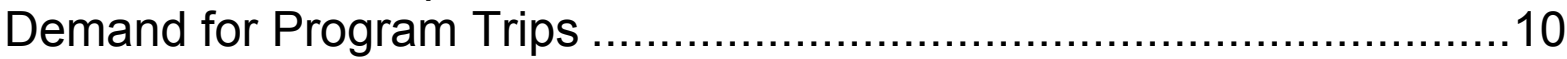

Demand for General Trips …………….....................................

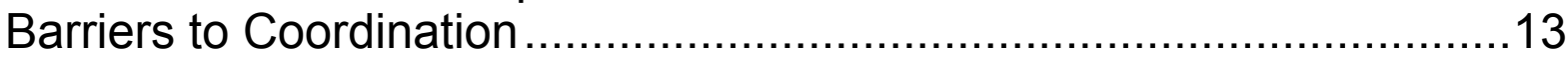

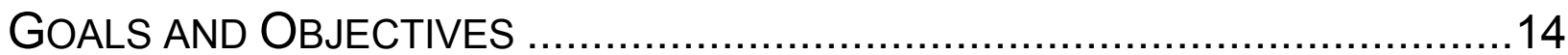

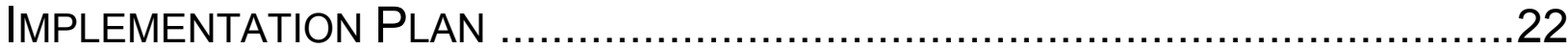

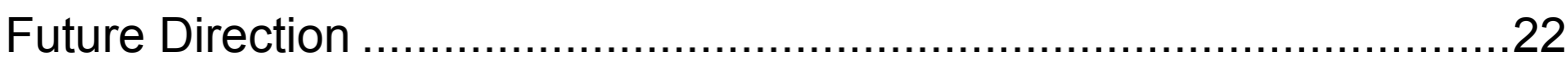

Actions to be Initiated Within One Year ...........................................25

Actions to be Initiated Within Two to Three Years .................................32 


\section{SERVICE PLAN}

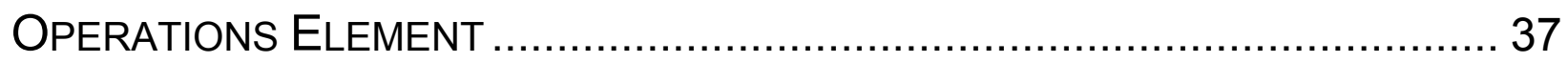

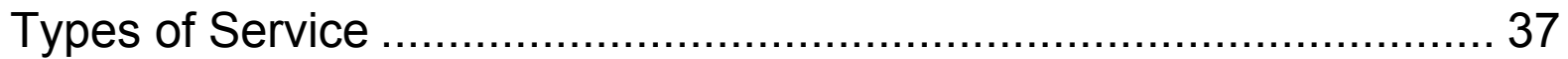

Days and Hours of Service ....................................................... 38

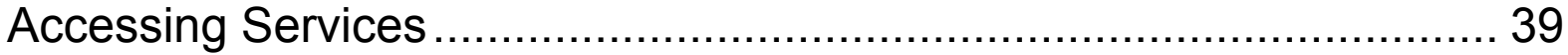

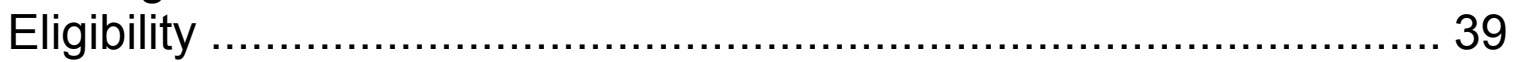

Prioritization..................................................................... 40

Transportation Operators and Coordination Contractors ..................... 41

Public Transit Utilization............................................................. 42

School Bus Utilization ............................................................ 42

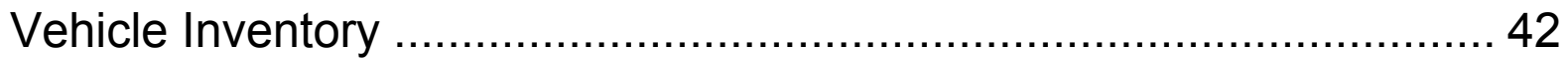

System Safety Program Plan Certification .......................................... 43

Intercounty Services ................................................................. 43

Natural Disaster/Emergency Preparedness....................................... 43

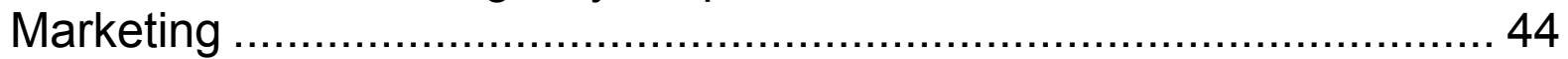

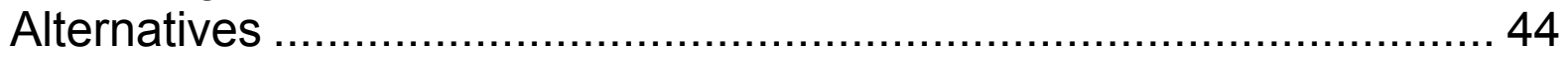

\section{QUALITY AssuRANCE}

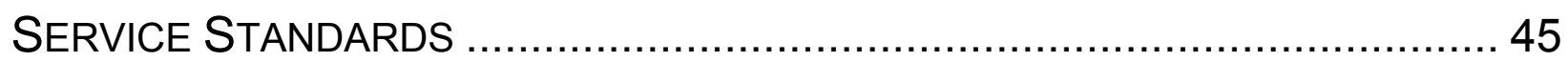

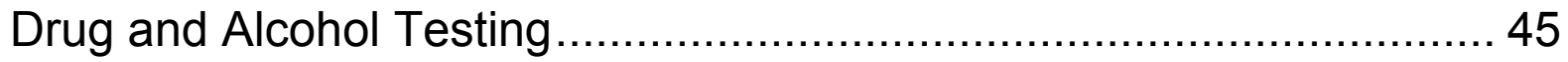

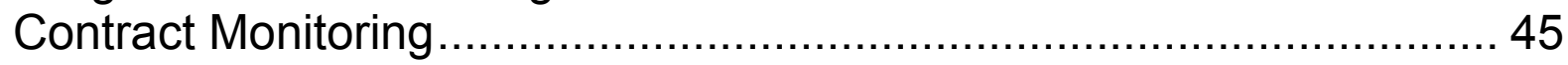

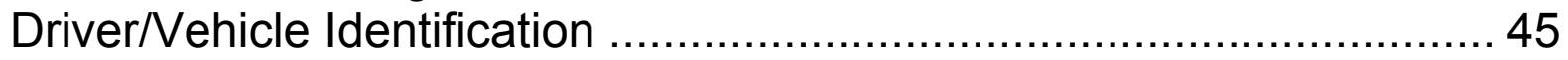

Local Toll-Free Numbers........................................................... 45

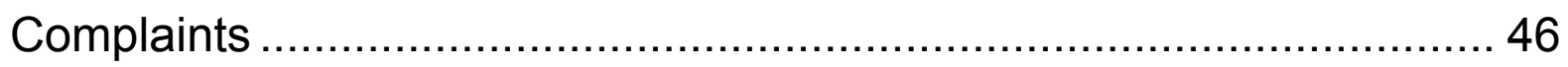

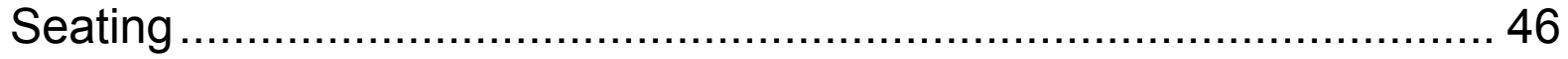

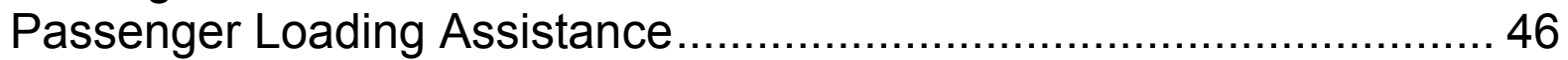

Smoking, Eating and Drinking ......................................................... 46

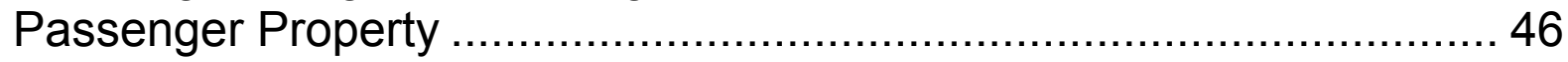

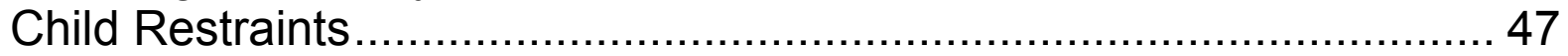

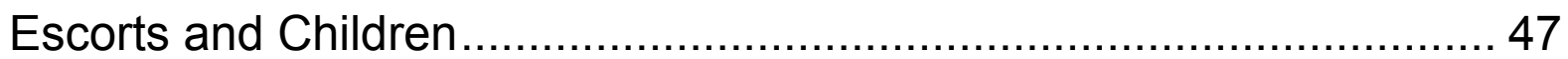

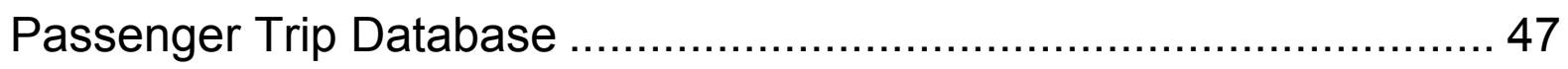

Pick-Up Window....................................................................... 48

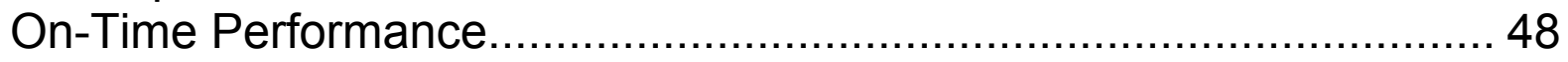

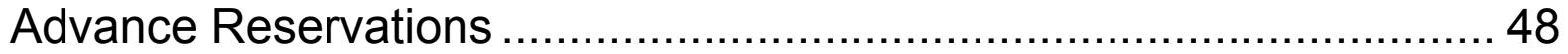

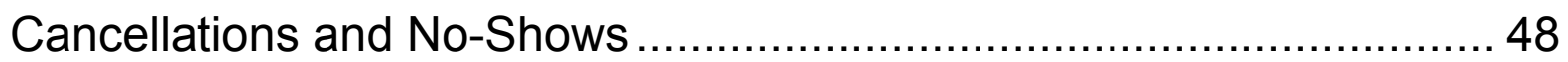

Driver Criminal Background Screening ……………….................... 50

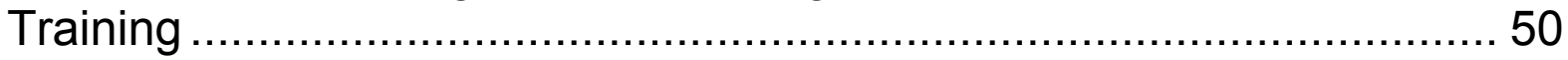




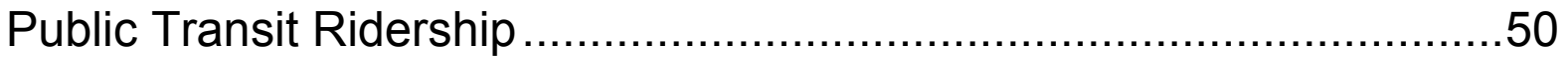

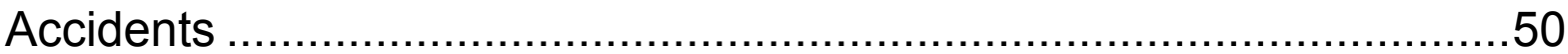

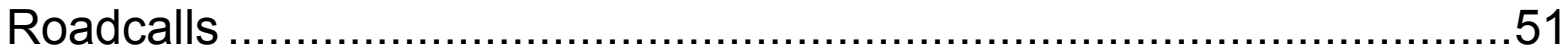

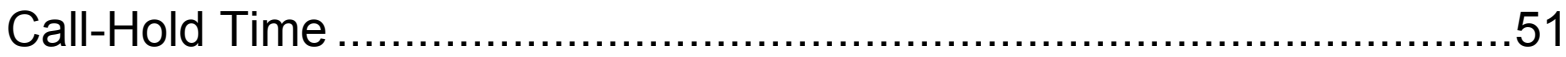

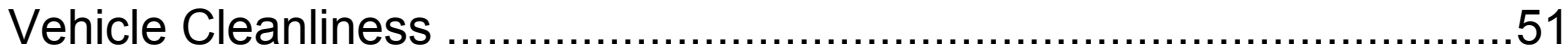

Vehicle Heating/Air Conditioning .....................................................51

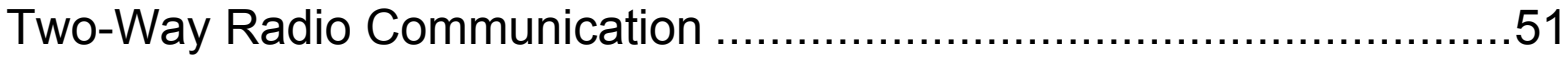

Out-of-Service-Area Trips ........................................................

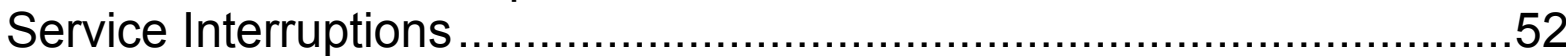

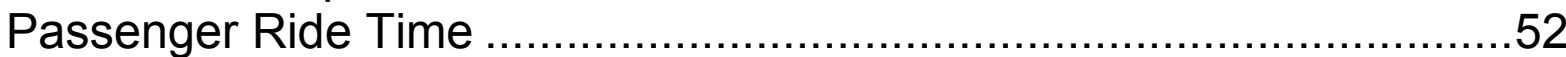

LOCAL GRIEVANCE PROCEDURE ...................................................52

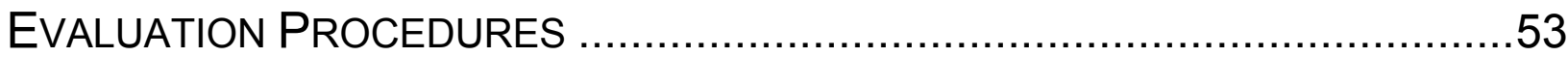

Community Transportation Coordinator ……………........................53

Operators and Coordination Contractors .............................................53

\section{Cost Revenue Allocation and Rate Structure}

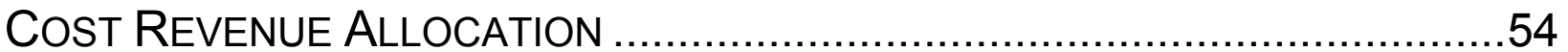

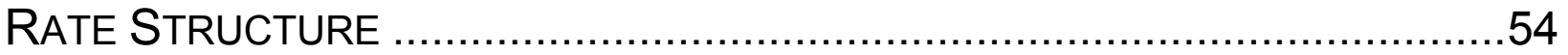

V. TREND ANALYSIS

CTC TREND ANALYSIS 


\section{APPENDICES}

APPENDIX A

Local Coordinating Board Membership

APPENDIX B

Vehicle Inventory

APPENDIX C

System Safety Service Plan Certification

APPENDIX D

Grievance Procedure

APPENDIX E

Financial Plan and Cost Effectiveness Worksheet 


\section{TDSP CeRTIFICATION}

The Volusia County Transportation Disadvantaged Local Coordinating Board (TDLCB) hereby certifies that an annual evaluation of the Community Transportation Coordinator was conducted consistent with the policies of the Commission for the Transportation Disadvantaged and all recommendations of that evaluation have been incorporated in this Service Plan. We further certify that the rates contained herein have been thoroughly reviewed, evaluated and approved. This Transportation Disadvantaged Service Plan was reviewed in its entirety and approved by this Board at an official meeting held on September 18, 2002.

Date Councilman Frank Bruno TDLCB Chairman

Approved by the Commission for the Transportation Disadvantaged:

Date

Jo Ann Hutchinson Executive Director 
TD Coordinating Board Roll Call

For Approval of Volusia County's

Transportation Disadvantaged Service Plan Update

September 18, 2002

\begin{tabular}{|c|c|c|c|c|}
\hline Name & Representing & Yes & No & Absent \\
\hline Frank Bruno & Elected Official & $\checkmark$ & & \\
\hline Patricia Antol & Veterans Affairs & $\boldsymbol{v}$ & & \\
\hline Anganie Durbal & FDOT & & & $\boldsymbol{v}$ \\
\hline Deweece Ogden & AHCA & & & $\boldsymbol{v}$ \\
\hline Leslie Richards & DCF & $\boldsymbol{v}$ & & \\
\hline Gail Camputaro & Elder Affairs & $\boldsymbol{v}$ & & \\
\hline Marilu Klopp & DLES & $\boldsymbol{v}$ & & \\
\hline Fred Miller & Volusia County School Board & & & $\boldsymbol{v}$ \\
\hline Mary Ellen Ottman & Citizen Advocate - User & $\boldsymbol{v}$ & & \\
\hline David Dixon & Citizen Advocate & $\boldsymbol{v}$ & & \\
\hline Ethel Drogan & Elderly Citizens & & & $\boldsymbol{v}$ \\
\hline Barbara Goldstein & Disabled & $\boldsymbol{v}$ & & \\
\hline Vacant & Private Non-Profit Provider & & & \\
\hline Reggie Williams & Economically Disadvantaged & $\boldsymbol{v}$ & & \\
\hline Kathy Davis & Mass Transit & $\boldsymbol{v}$ & & \\
\hline
\end{tabular}


viii 


\section{DeVelopment Plan}

\section{INTROduction to the SERVice AREA}

\section{Background}

Volusia County Government serves as the Community Transportation Coordinator (CTC) for the Transportation Disadvantaged (TD) program in Volusia County. Volusia County was designated as the CTC in November 1993. The day-to-day operation of the public transit system is delegated to VOTRAN through a management contract and includes fixed-route, paratransit, trolley/beach tram and commuter assistance services. VOTRAN operates under the County umbrella of Community Services.

Volusia County was re-authorized under a Memorandum of Agreement (MOA) as the CTC for a three-year term beginning October 1, 1999 and ending September 30, 2002. Figure 1 shows the organizational structure of the Volusia County CTC.

VOTRAN is a partial broker system, with the majority of trips provided inhouse. The remainder of trips are contracted to eight small private-for-profit operators, along with incidental use of taxicabs.

VOTRAN also has coordination agreements with two agencies, Duvall Home and Good Samaritan Inn. They have secured vehicles under the Section 5310 program for the primary purpose of transporting their own clients. These trips are part of the coordinated system and reported on the Annual Operating (AOR). The entire fleet of directly-operated and contracted vehicles is equipped with lifts that are in compliance with the Americans with Disabilities Act of 1990 (ADA). 
As the CTC, VOTRAN performs all elements of coordination for the TD program in Volusia County, e.g., planning, public information and marketing, call intake, eligibility and certification, reservations, scheduling, transportation, reporting, cost-sharing and information sharing.

Figure 1

Organization Chart for Volusia County's TD Program

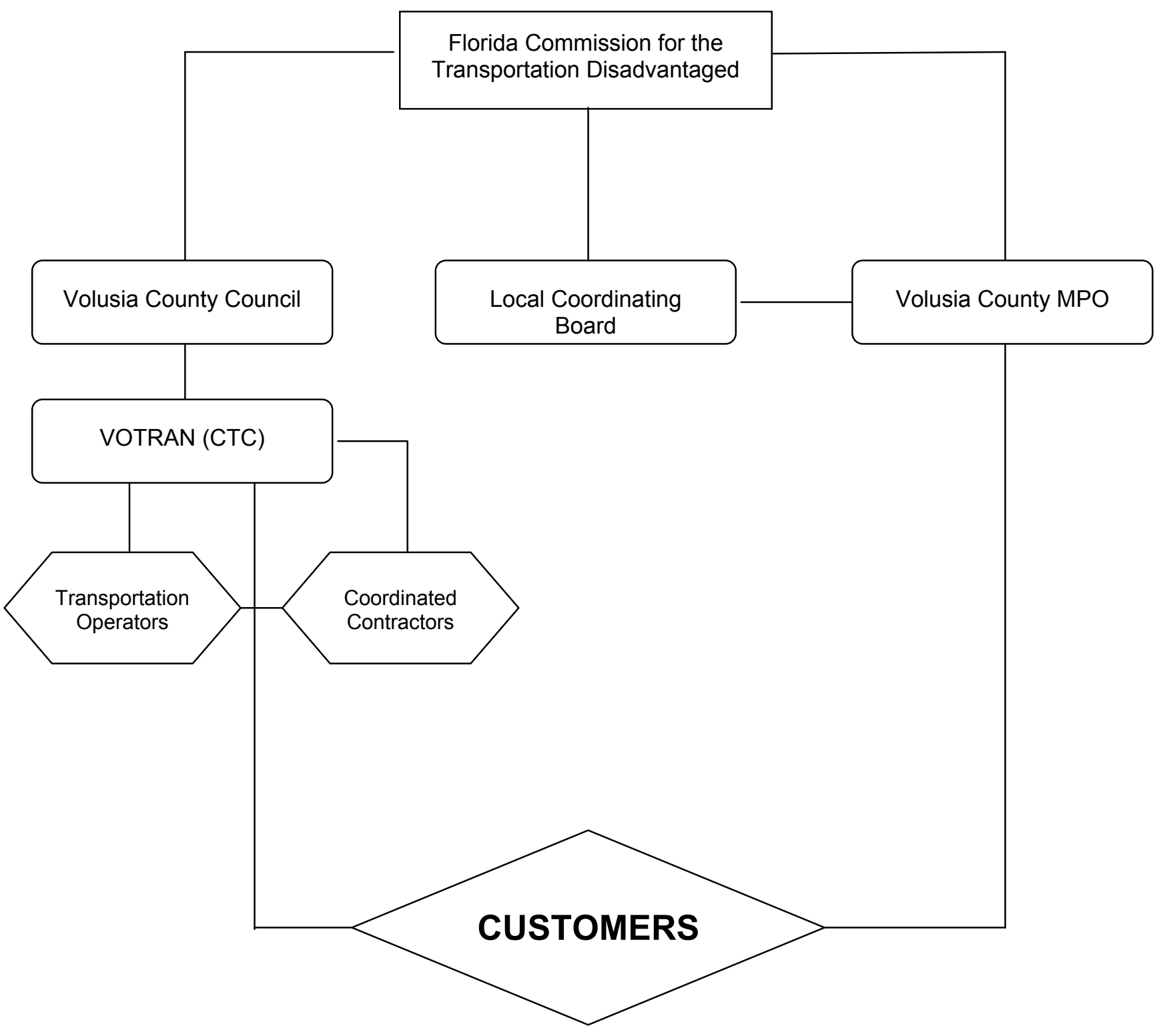




\section{Consistency Review of Other Plans}

Pertinent portions of the following plans were reviewed in order to determine consistency and identify existing goals, objectives and policies that support transit.

- Local Government Comprehensive Plans

- Transit Development Plan for VOTRAN

- Long Range Transportation Plan for Volusia County

- Transportation Improvement Program for Volusia County

- Commission for the Transportation Disadvantaged 5 and 20 year plans

This Service Plan is consistent with all of the above-referenced plans. By reducing the number of individual trips and vehicles on the road, the coordinated system helps to address concerns expressed in these plans regarding roadway safety and capacity constraints.

\section{Local Coordinating Board Certification}

See Appendix A for Volusia County Local Coordinating Board Membership.

\section{Service Area Profile and Demographics}

\section{Description}

Volusia County is comprised of 1207 square miles and located on the east coast of central Florida, approximately 50 miles East of Orlando, and 100 miles South of Jacksonville. The County has two urbanized areas, the greater Halifax area located on the east side of Interstate 95, and the Deltona area 
located in the southwest portion of the County. The majority of the population is concentrated in the eastern urbanized portion of the County.

\section{Demographics}

There are sixteen incorporated municipalities in Volusia County. Due to the favorable weather and beaches, Volusia County experiences visitors all year round, with the main tourist season from January to June. Major events, such as Bike Week, Nascar Races, and Spring Break, create traffic congestion in the core area of Daytona Beach. Employment, medical and social services are mainly concentrated in the Daytona Beach area.

\section{Land Use}

Commercial, medical and service land uses are located along major arterials - US 1, International Speedway Boulevard, Granada Boulevard, and Dunlawton in East Volusia County, and the US $17 / 92$ corridor in west Volusia County. The difficulty in operating public transit in Volusia County is that population density (and accompanying commercial land use) is located in two pockets, one on the east side running the entire length of the County, and one on the west side running along the US $17 / 92$ corridor. The area in between is sparsely populated. Adding to the challenge of providing countywide service is the fact that people living in the southwestern portion of the County are sometimes situated closer to Seminole County medical facilities than to medical facilities within Volusia.

\section{Population}

According to the U.S. Census Bureau, Volusia County's 2000 population count was 443,343 , indicating $20 \%$ growth in the past 10 years. Table 1 shows growth and density for Volusia County and Florida. 
Table 1

Population and Density

\begin{tabular}{|c|c|c|c|c|}
\hline Area & $\begin{array}{c}\text { Population } \\
\text { (1990) }\end{array}$ & $\begin{array}{c}\text { Population } \\
\mathbf{( 2 0 0 0 )}\end{array}$ & $\begin{array}{c}\text { Population } \\
\text { Growth } \\
(\mathbf{1 9 9 0 - 2 0 0 0 )}\end{array}$ & $\begin{array}{c}\text { Density (2000) } \\
\text { (persons per } \\
\text { square mile) }\end{array}$ \\
\hline Volusia & 370,737 & 443,343 & 0.20 & 402 \\
\hline Florida & $12,937,926$ & $15,982,378$ & 0.24 & 296 \\
\hline
\end{tabular}

Source: 1990 and 2000 population counts provided by U.S. Census Bureau

\section{Age}

Volusia's median age is 42 , which continues to be higher than the State average of 39 years. Figure 2 shows that Volusia's age distribution is similar to the State of Florida, but the most notable difference is that Volusia has a higher population of people aged 65 and over, and a lower distribution of people 20-44 years of age.

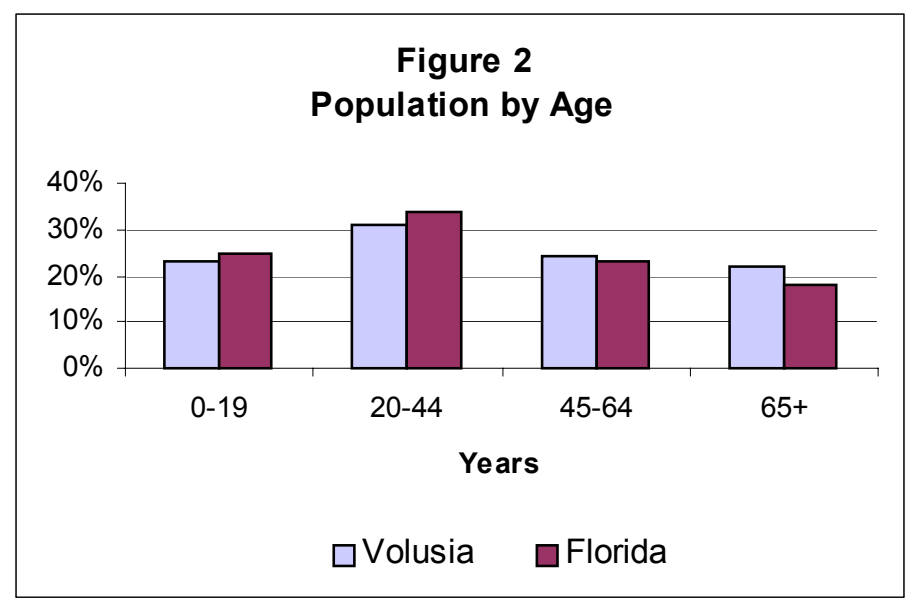

Income

Figure 3 shows the distribution of household income in Volusia County and Florida. Compared to the State, Volusia has a lower percentage of households with incomes over $\$ 50,000$, and a higher percentage of households with incomes between $\$ 15,000$ and $\$ 24,999$. Accordingly, the 2000 median per 
capita personal income (PCPI) in Volusia (as recorded by the Bureau of Economic Analysis) was $\$ 22,574$, compared to a state average of $\$ 27,764$. Like age, income is an important factor in determining the usage of public and social services.

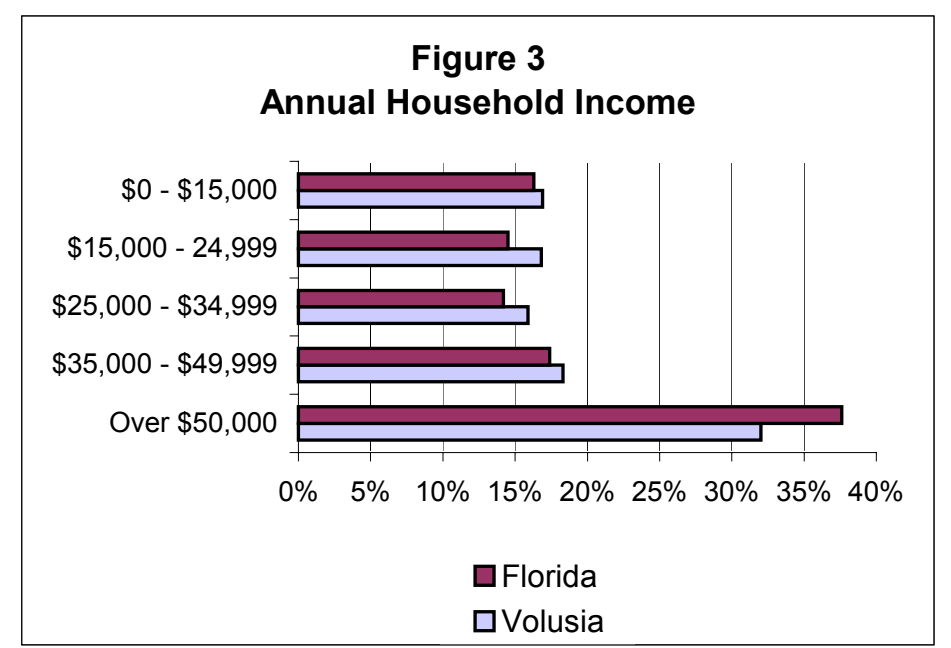

\section{Employment}

In 2000 , the Volusia County civilian labor force was 174,723 people, with a very low unemployment rate of $2.8 \%$, compared to the State's average unemployment rate of $3.6 \%$. Table 2 compares the County and State unemployment rates and labor force. Although Volusia has a slightly higher average age, the percentage of population age 15-64 in the labor force was much lower than the State average. The most recent data available, for June 2002 , show that Volusia's unemployment rate was the same as the State, at $5.4 \%$. 
Table 2

Labor Force Comparison (2000)

\begin{tabular}{|l|c|c|c|}
\hline \multicolumn{1}{|c|}{ Area } & Labor Force & $\begin{array}{c}\text { \% of age 15-64 } \\
\text { in Labor Force }\end{array}$ & $\begin{array}{c}\text { Rate of } \\
\text { Unemployment }\end{array}$ \\
\hline Volusia & 174,723 & $64.3 \%$ & $2.8 \%$ \\
\hline Florida & $7,490,000$ & $73.8 \%$ & $3.6 \%$ \\
\hline
\end{tabular}

Source: Florida Research and Economic Database, www.labormarketinfo.com

Halifax Community Health Systems is the largest non-government employer in Volusia County, employing more than 4,500 people. Other major employers include: Volusia County School Board, Nascar, Volusia County, State of Florida, and Publix. ${ }^{1}$

Major Paratransit Trip Generators

Major paratransit trip generators/attractors in Volusia County (in no particular order) are:

Halifax Hospital

Ormond Memorial Hospital

Peninsula Medical Center

Halifax Professional Center

Halifax Oncology Center

Florida Health Care

Wound Care Centers

Gambro Dialysis

BMA dialysis

New Smyrna Dialysis

Halifax Urgent Care

Lab Corp

Quest Diagnostic Laboratory

Suncoast Imaging

Cora Rehabilitation

Premier Rehabilitation

Varsity Rehabilitation Centers
West Volusia Memorial Hospital

Florida Hospital

Volusia Mall

Wal-Mart Super Center

Daytona Beach Community College

Veterans Administration

Dunlawton Square

Volusia Square

Mason Nova Plaza

Senior Dining Centers

North Gate Plaza

Volusia Point Square

Vocational Rehabilitation

Department of Children \& Families

Ormond Medical Center

Fish Memorial Hospital

\footnotetext{
${ }^{1}$ Volusia County Economic Development Council, www.floridabusiness.org/topemployers.htm
} 


\section{Service Analysis}

This section presents estimates regarding the need and demand for transportation services among the Transportation Disadvantaged (TD) population in Volusia County. It provides a quantitative transportation needs profile for the applicable TD populations and indicates unmet need for transportation in the Volusia County service area.

\section{Forecasts of TD Population}

There are two categories of TD population in the State of Florida, the difference between which are specifically related to funding arrangements. The first group is the "potential TD population" (also known as TD Category I). This potential TD population includes disabled, elderly, low-income persons, and children who are "high-risk" or "at-risk."

The second group of TD population (also known as TD Category II) includes those persons who are unable to transport themselves or to purchase transportation. These persons are eligible to receive the same subsidies as those in Category I, plus they are eligible to receive TD Trust Fund monies for non-sponsored general trips. Thus, this population group is actually a subset of the potential TD population.

Table 3 presents forecasts of the TD Population (Category I) and the Potential TD Population (Category II) in Volusia County. These forecasts were developed using the methodology outlined in the 1993 CUTR report, Methodology Guidelines for Forecasting TD Transportation Demand at the County Level.

Table 3

Forecasts of TD Populations in Volusia County 


\begin{tabular}{|l|c|c|c|c|c|c|}
\hline & $\mathbf{2 0 0 2}$ & $\mathbf{2 0 0 3}$ & $\mathbf{2 0 0 4}$ & $\mathbf{2 0 0 5}$ & $\mathbf{2 0 0 6}$ & $\mathbf{2 0 0 7}$ \\
\hline Category I & 192,350 & 196,028 & 199,790 & 203,639 & 210,788 & 218,207 \\
\hline Category II & 46,148 & 46,928 & 47,724 & 48,539 & 50,124 & 51,765 \\
\hline
\end{tabular}

Tables 4 and 5 break down the Potential TD Population and TD Population groups in Volusia County. These estimates are derived from the CUTR publication Florida Statewide Transportation Disadvantaged Plan: Population and Demand Forecasts 1996 - 2015, July 1996. Persons in either of these population groups may be heavily dependent on some form of public transportation.

Table 4

2002 Volusia County Potential Transportation

Disadvantaged Population (Category I)

\begin{tabular}{|l|c|c|}
\hline \multicolumn{1}{|c|}{ Segments } & $\begin{array}{c}\text { Population } \\
\text { Estimates }\end{array}$ & $\begin{array}{c}\text { Percent of } \\
\text { Total } \\
\text { Potential TD }\end{array}$ \\
\hline Disabled, Non-Elderly, Low Income & 3,198 & $1.6 \%$ \\
\hline Disabled, Non-Elderly, Non-Low Income & 20,315 & $10.6 \%$ \\
\hline Disabled, Elderly, Low Income & 3,475 & $1.8 \%$ \\
\hline Disabled, Elderly, Non-Low Income & 36,470 & $19.0 \%$ \\
\hline Non-Disabled, Elderly, Low Income & 7,628 & $4.0 \%$ \\
\hline Non-Disabled, Elderly, Non-Low Income & 80,048 & $41.6 \%$ \\
\hline Non-Disabled, Non-Elderly, Low Income & 41,216 & $21.4 \%$ \\
\hline Total Potential Transportation Disadvantaged & 192,350 & $100 \%$ \\
\hline
\end{tabular}

Source: Estimates prepared by CUTR using the methodology described in Methodology Guidelines for Forecasting TD Transportation Demand at the County Level, May 1993. 
Table 5

2002 Volusia County Transportation

Disadvantaged Population (Category II)

\begin{tabular}{|l|c|c|}
\hline \multicolumn{1}{|c|}{ Segments } & $\begin{array}{c}\text { Population } \\
\text { Estimates }\end{array}$ & $\begin{array}{c}\text { Percent of } \\
\text { Total TD }\end{array}$ \\
\hline Transportation Disabled, Non-Elderly, Low Income & 1,466 & $3.2 \%$ \\
\hline Transportation Disabled, Non-Elderly, Non-Low Income & 9,311 & $20.2 \%$ \\
\hline Transportation Disabled, Elderly, Low Income & 2,032 & $4.4 \%$ \\
\hline Transportation Disabled, Elderly, Non-Low Income & 21,323 & $46.2 \%$ \\
\hline $\begin{array}{l}\text { Non-Transportation Disabled, Low Income, No Auto, } \\
\text { No Fixed-Route Transit }\end{array}$ & 12,016 & $26.0 \%$ \\
\hline Total Transportation Disadvantaged Population & 46,148 & $100 \%$ \\
\hline
\end{tabular}

Source: Estimates prepared by CUTR using the methodology described in Methodology Guidelines for Forecasting TD Transportation Demand at the County Level, May 1993.

\section{Demand for Program Trips}

Persons in Category I are eligible to receive governmental and social service subsidies for program trips. A program trip is one made by a client of a government or social service agency for the purpose of participating in a program of that agency. Examples of program trips are Medicaid trips, trips to congregate meal sites, or trips to job training facilities.

The estimated demand for program trips is shown in Table 6. Program Trip demand is dependent upon the existence of the program to which the potential TD population group is transported. For example, demand for trips to sheltered workshops exists only because there are sheltered workshop programs. Thus, the demand for program trips is equal to the number of trips required to take advantage of the service offered by the program. Therefore, the demand for program trips depends on the funding level for the various social service programs. 
Table 6

Forecasts of Volusia County

Program Trip Demand and Supply

\begin{tabular}{|c|c|c|c|}
\hline Year & $\begin{array}{c}\text { Potential TD } \\
\text { Population } \\
\text { (Category I) }\end{array}$ & $\begin{array}{c}\text { Demand for } \\
\text { Program Trips }\end{array}$ & $\begin{array}{c}\text { Supply of } \\
\text { Program Trips }\end{array}$ \\
\hline 2002 & 192,350 & 632,159 & 632,159 \\
\hline 2003 & 196,028 & 644,802 & 644,802 \\
\hline 2004 & 199,790 & 657,698 & 657,698 \\
\hline 2005 & 203,639 & 670,852 & 670,852 \\
\hline 2006 & 210,788 & 684,269 & 684,269 \\
\hline 2007 & 218,207 & 697,955 & 697,955 \\
\hline
\end{tabular}

NOTE: Estimates prepared by CUTR using the methodology described in the 1993 CUTR Report Methodology Guidelines for Forecasting TD Transportation Demand at the County Level, May 1993.

\section{Demand for General Trips}

General trips are trips made by Transportation Disadvantaged persons (Category II) to destinations of their choice (not to agency programs). Examples of general trips are trips to work or grocery stores and nonMedicaid medical trips. Deriving the demand for general trips is different than for program trips. The methodology developed to forecast demand for general trips involves the use of trip rates derived in a study of paratransit demand conducted in 1990 for the San Francisco Bay Area Metropolitan Transportation Commission by Crain \& Associates, Inc. and others (San Francisco Bay Area Regional Paratransit Plan: Final Report). The trip rates were developed from the actual experiences of paratransit systems around the country that were meeting most or all of the trip demand in their service areas. The use of these trip rates has been recommended by the Federal Transit Administration for estimating demand for ADA complementary paratransit. 
Total demand for general trips is simply the TD population multiplied by the trip rates. The TD population (rather than the Potential TD population) was used to forecast demand, because the TD population is the pool of persons eligible for general trips funded by the state. Table 7 shows the forecasts of the Volusia County TD population, as well as demand and supply estimates for general trips by the TD population for the years 2002 through 2007 .

A gap exists between demand for general trips and the supply of these trips. Unmet demand refers to demand that currently exists in the TD transportation market, but is not being met due to factors such as funding, price, convenience, comfort, eligibility, and the availability of other transportation modes.

Table 7

Forecasts of Volusia County TD General Trip Demand and Supply

\begin{tabular}{|c|c|c|c|c|}
\hline Year & $\begin{array}{c}\text { TD Population } \\
\text { (Category II) }\end{array}$ & $\begin{array}{c}\text { Demand for } \\
\text { General Trips }\end{array}$ & $\begin{array}{c}\text { Supply of } \\
\text { General Trips }\end{array}$ & $\begin{array}{c}\text { Unmet Demand } \\
\text { for General } \\
\text { Trips }\end{array}$ \\
\hline 2002 & 46,148 & 600,293 & 116,836 & 483,457 \\
\hline 2003 & 46,928 & 610,439 & 119,173 & 491,267 \\
\hline 2004 & 47,724 & 620,794 & 121,556 & 499,238 \\
\hline 2005 & 48,539 & 631,395 & 123,987 & 507,408 \\
\hline 2006 & 50,124 & 652,013 & 126,467 & 525,546 \\
\hline 2007 & 51,765 & 673,359 & 128,996 & 544,363 \\
\hline
\end{tabular}

NOTE: Estimates prepared by CUTR using the methodology described in the 1993 CUTR report Methodology Guidelines for Forecasting TD Transportation Demand at the County Level, May 1993.

It should be noted that the figures related to the demand and supply of TD general purpose trips in Volusia County include some trips that will also fall under the category of ADA complementary paratransit services. The ADA provides for unconstrained delivery of paratransit trips for persons who cannot 
use the fixed-route bus system due to the nature and/or extent of their disability. Persons may be certified as eligible for ADA paratransit trips, as well as TD general purpose trips. Therefore, the figures for unmet demand included in Table 7 are inflated and reflect some duplication in the calculation of trip demand.

\section{Barriers to Coordination}

VOTRAN continues to work diligently with agencies in Volusia County to strengthen the coordination of transportation in the County, but barriers exist in the following areas:

- Even with increased funding, there is more demand for TD services than supply.

- Some social service agencies have had their transportation funding reduced, causing the burden to be shifted to TD. There is a concern that some agencies see TD as an opportunity to reduce their own budgets for transportation services.

- A large number of ADA complementary paratransit trips may actually be agency-sponsored trips.

- Because there are no sanctions for non-payment, collection of Medicaid co-payment continues to cause hardship.

- Volusia's population is concentrated in the eastern portion of the County, making service delivery difficult in the western portion. Clients who are located in the western portion of Volusia County are closer to facilities located in Seminole County, making service delivery even more challenging. In addition to scheduling challenges, trip mileage is increased 
and opportunities for multi-loading are decreased, causing the cost per trip to rise.

- In Volusia County, the CTC does not contribute toward the decision-making process regarding awards of grant monies for Section 5310 vehicles. Coordination Agreements with the CTC should be secured by the non-profit agency prior to award of Section 5310 funds by FDOT.

- Required federal, State and local program standards add cost to providing service, making it difficult to bring programs with no transportation budgets under the CTC umbrella, such as MedWaiver.

\section{GoALS AND OBJectives}

The goals for VOTRAN focus on five interrelated policy areas important to the effective operation of a transit system.

- Availability, efficiency, and safety of service

- Passenger amenities and marketing;

- Transportation planning coordination;

- Funding; and

- Public Involvement

Each objective addresses, in a broad context, actions to be taken in order to achieve the stated goal. 


\section{GOAL 1}

\section{Participate in and Ensure Availability of an Effective Public Transpor- tation System that Safely and Efficiently Moves People Throughout, In, and Out of Volusia County.}

Objective 1.1

Continue to operate as the mobility manager for Volusia County, operating/coordinating transit and paratransit service, carpools, vanpools, and other TDM activities/strategies.

\section{Objective 1.2}

Provide the safest possible transit service; include safety provisions for pedestrians, bicyclists, and persons with disabilities at all transit facilities.

Objective 1.3

Comply with all requirements of the Americans with Disabilities Act of 1990 (ADA); improve access to transit for persons with disabilities.

\section{Objective 1.4}

Optimize the transit system and facilities, for both fixed-route and paratransit operations, to provide current level of service or better throughout the area.

Objective 1.5

Increase frequency of service on most congested corridors and busiest routes.

Objective 1.6

Increase the span of service, specifically to include night service on routes based on need. 
Objective 1.7

Use appropriate-size vehicles, and develop flexible community bus routes to maximize ridership.

Objective 1.8

Enhance Park-and-Ride program, express bus service, and the vanpool program.

Objective 1.9

Maintain, improve, or expand service to major intermodal facilities, terminals, employment centers, schools, activity centers, parks, recreational areas, cultural facilities, and social and medical facilities.

Objective 1.10

Continue to monitor overall system performance as well as individual route performance.

Objective 1.11

Provide a network of reasonable transit and paratransit connections to counties adjacent to Volusia County.

Objective 1.12

Maximize investment in beach trolley/tram service \& coordinate service with ultimate beach parking solutions.

Objective 1.13

Explore the potential of rail modes for future use within the county and connecting to surrounding counties. 


\section{Objective 1.14}

Continue to monitor ridership market through on-board surveys, customer satisfaction surveys, etc.

\section{GOAL 2}

Provide New and Maximize the Use of Existing Quality Passenger Amenities to Enhance Bus Service and Attract Discretionary Riders

\section{Objective 2.1}

Provide more shelters/benches at highly used bus stops, transfer points, and other locations as necessary.

Objective 2.2

Work with the MPO and others to develop a standard for placement of bus stops, benches, and shelters that can be implemented countywide.

Objective 2.3

Install bicycle racks at those bus stops where heavy bicycle use has been noted.

Objective 2.4

Explore feasibility of using Advanced Public Transportation System (APTS) Technology, such as smart cards, to improve amenities for riders.

Objective 2.5

Review the effectiveness and user-friendliness of current route and schedule information; make improvements as necessary and ensure its availability to both current and potential system users. 


\section{Objective 2.6}

Continue community outreach/education programs for fixed-route and paratransit services.

\section{Objective 2.7}

Maintain the VOTRAN bus stop inventory to assess the accessibility of existing stops and catalog existing amenities (e.g., phones, lighting, shelters, benches, etc.) at each stop.

\section{Objective 2.8}

Continue to increase the visibility of VOTRAN through creative marketing efforts.

Objective 2.9

Continue to coordinate transit services with other transportation providers in and adjacent to Volusia County.

\section{GOAL 3}

Coordinate the Transit System and Its Improvements with Transportation Planning Efforts of All Government Entities

Objective 3.1

Initiate planning to provide service in projected growth areas of the county.

Objective 3.2

Coordinate with local governments for the construction of accessible sidewalks, bus stops, and other bus stop improvements along existing roadways. 


\section{Objective 3.3}

Continue to coordinate with state and local government and transportation agencies the integration of transit needs/amenities into the land use planning and development process.

Objective 3.4

Coordinate and encourage intermodal strategies that lessen the dependency on single-occupant vehicles.

\section{Objective 3.5}

Continue to ensure the coordination of all comprehensive plans and other related planning documents.

Objective 3.6

Encourage local government to maintain higher densities near arterial and urban collector public transportation corridors.

\section{Objective 3.7}

Encourage local government to remove land-use barriers that may restrict the use of public transportation.

\section{Objective 3.8}

Require developers to include public transportation-compatible designs in their projects (e.g., parking lot requirements, bus shelters, bike facilities, etc.)

Objective 3.9

Coordinate with the Florida Department of Transportation and agencies related with the I-4 Master Plan as it relates to rail service into, adjacent to, and within Volusia County. 


\section{GOAL 4}

\section{Provide a Transit System that is, to the Maximum Extent Possible, Financially Feasible by Securing Adequate Funding}

\section{Objective 4.1}

Maintain current Federal, State, and County funding sources for the fixedroute and paratransit systems.

\section{Objective 4.2}

Identify and evaluate alternative funding sources for the fixed-route and paratransit systems.

Objective 4.3

Secure a long-term dedicated funding source for the fixed-route and paratransit systems.

Objective 4.4

Secure funding source for any future rail feeder service designed to link rail and intermodal facilities.

Objective 4.5

Continue to expand bus pass program.

Objective 4.6

Strive to develop, manage, operate, and maintain, to the maximum extent possible, a cost-feasible transit system.

Objective 4.7

Provide transit service that is, to the maximum extent possible, effective and efficient and is operated in a fiscally responsible manner. 


\section{Objective 4.8}

Evaluate appropriate technologies to enhance service delivery (e.g., scheduling, vehicle location, etc.)

\section{GOAL 5}

\section{Maintain a Proactive Public Involvement Process}

\section{Objective 5.1}

Provide early and continuing opportunities for the public to express views that relate to transit services, plans, and improvement programs and projects (e.g., surveys, grievance process, interviews, workshops, etc.).

\section{Objective 5.2}

Provide complete information about transit issues, adequate public notice of time and place, and full public access to open public meetings where matters related to transit programs are being considered.

\section{Objective 5.3}

Allow time for public review and comment at key decision points in the transit planning process.

\section{Objective 5.4}

Utilize public and expert opinions about the overall quality and frequency of transit services in optimizing fixed-route and paratransit services.

\section{Objective 5.5}

Educate the community on the use of the public transportation system through the following methods: (a) train the public how to use and/or access the system, (b) educate the public about misuses or abuses of the transportation system, and (c) promote the one dollar tag contribution in support of the transportation disadvantaged program. 
Objective 5.6

Continue to provide opportunities for public officials to be exposed to and educated about public transportation and VOTRAN's services, in particular.

\section{Objective 5.7}

Continue to utilize the Transportation Disadvantaged Local Coordinating Board (TDLCB) and the MPO Citizens Advisory Committee to assist in providing input to management on all aspects of service planning.

\section{IMPLEMENTATION PLAN}

\section{Future Direction}

1. Respond to Growth in Volusia County

This recommendation stresses the need to provide transit service in growing areas of Volusia County. The primary benefits are twofold. First, it ties the need for transit service to land use development and population growth patterns in Volusia County. Second, it clearly permits and encourages growth in the transit system in response to these and similar changes. In essence, the transit network is treated like any other part of the transportation system in the county in that it will expand to meet the emerging travel demands of growth areas.

Service expansion, as discussed previously, can be expensive, especially if the new service area is suburban in character. Also, this approach leaves the question of the appropriate level of service unanswered, and so runs the risk of spreading the transit agency too thin. 


\section{User-Side Subsidized Taxi Service}

The user-side subsidy service concept has been identified as a potential method of serving primarily low-income citizens or seniors with a need for personal mobility. In a user-side subsidy program, patrons are charged a portion of the fare associated with a demand-response trip and the remainder of the cost for the trip is subsidized by the program's implementing agency. Taxicab companies typically provide the trips delivered through user-side subsidy programs. These programs have a high potential for effectiveness in areas with low demand or low density, or at specific times of the day (late evening service), or specific days of the week (Sunday service). Taxi-based user-side subsidy programs are currently operating in many large cities in the United States, such as Houston, Los Angeles, San Francisco, Oklahoma City, and Seattle.

Although each program is designed according to each area's unique mobility needs, some general parameters can be applied to taxi-based user-side subsidy programs. Customers are typically sold taxi vouchers worth a certain dollar amount toward a cab ride (e.g., \$10.00) at a reduced cost. The amount of the subsidy passed on to consumers varies from 40 percent to 90 percent. For example, in a program with a 50 percent subsidy, the consumer would be charged $\$ 5.00$ for a $\$ 10.00$ taxi voucher. The customer then makes a trip with a designated taxi company and is responsible for any portion of the total fare that exceeds the total value of the voucher.

\section{Community Transportation Pool}

The concept of a community transportation pool is to expand the existing transportation network available to residents and visitors of a county to include existing transportation resources currently not providing general purpose, general public transportation. The objective of the transportation pool is to bring together, under one coordinated umbrella, the variety of transportation resources that exist in the county. Because coordination is 
contingent upon the establishment of mutually beneficial relationships, the pool includes mechanisms for community transportation providers to join the pool without incurring excessive financial burdens while concurrently ensuring reliable and safe services to the public. Therefore, the community transportation pool includes incentives for participation in return for commitments to provide services under the pool, which would be administered by a particular implementing agency, such as a transit system or Community Transportation Coordinator.

Eligible providers to participate in the pool would include those agencies/entities that:

- Are privately funded, non-profit and provide transportation to specific market segments;

- Are privately funded, non-profit and provide transportation to persons meeting the definition of "transportation disadvantaged;"

- Have available vehicles to provide transportation services beyond those needed by the agency; and

- Are service providers that do not provide transportation as a primary mission of the agency.

Specifically prohibited from participating in the pool could be any public transportation providers with transportation as a primary mission and all for-profit operators.

Funding for pool expenses could come from a consortium of sources including but not limited to the county in which it operates, the Commission for the Transportation Disadvantaged, the Florida Department of Transportation, municipal governments, private foundations, and private donations or endowments. To CUTR's knowledge, no program of this nature, scope, or concept has ever been attempted or accomplished 
wherein efforts to coordinate providers has actually entailed financial resources to make coordination more feasible, palatable, and desirable. As a result, the nature of this concept is likely to be very desirable to the Commission for the Transportation Disadvantaged and the Florida Department of Transportation to invest in a pilot program and test the feasibility for wider application.

\section{Actions to be Initiated Within One Year}

1. Pursue the Establishment of a Long-Term Dedicated Funding Source for VOTRAN.

VOTRAN has been receiving the revenue from one cent of the recently approved five-cent local option gas tax. It is estimated that one cent of gas tax generates approximately $\$ 1$ million of revenue annually. Unfortunately, this revenue has supplanted the level of its previous county funding, rather than supplementing it.

Currently, Palm Beach County, Broward County, and Alachua County all dedicate some portion of their local option gas tax revenues to transit. Dade County does not dedicate any of its local option gas tax revenue specifically to transit; however, Miami-Dade Transit does receive an allocation from this source.

Volusia County should also continue to work toward a permanent source of dedicated funding for future VOTRAN improvements. One available option that may be used to help fund any recommended improvements is an increase in the County's sales tax. Currently, Volusia County is eligible to levy up to an additional 2.5 percent of local discretionary sales surtaxes (up to 1 percent for the charter county transit system surtax, up to 1 percent for the local government infrastructure surtax, and up to 0.5 percent for the school capital outlay surtax). If, for example, the County 
elected to levy the full 1 percent of the transit system surtax, it is estimated that this additional one-cent of sales tax would generate approximately $\$ 41.7$ million of revenue annually. (It should be noted that, currently, of the five counties eligible to levy the charter county transit system surtax, only Duval County has taken advantage of this opportunity, and only at 0.5 percent.) It is also possible that the County may want to revisit the gas tax distribution for the purpose of increasing VOTRAN's allocation. Regardless of origin, a dedicated funding source will help ensure the continued fiscal health of the system.

2. Continue to Seek Dedicated Sources of Funding to Minimize the Prioritization of TD Non-Sponsored Trips.

Since VOTRAN assumed the role of CTC in 1994, paratransit ridership has increased from 66,848 to 318,439 annual trips. Reductions in federal and state operating assistance suggest that future service demands will exceed VOTRAN's anticipated financial capabilities. In order to bring the demand for TD non-sponsored trips in line with financial capacity, VOTRAN has implemented trip priorities as established by the Volusia County Transportation Disadvantaged Local Coordinating Board. However, trip priorities can negatively impact the future mobility of the transportation disadvantaged population of Volusia County. Therefore, it is recommended that VOTRAN seek to minimize the prioritization of TD non-sponsored trips by identifying and securing additional dedicated sources of funding for the TD non-sponsored trips.

3. Use a Strict Certification Process for ADA Eligibility.

The Americans with Disabilities Act of 1990 clearly spells out the criteria for ADA eligibility and certification. While it is up to the local transit agency to determine whether or not to apply more liberal standards, it must also be determined whether or not the funds and capacity are available to do so. 
Obviously, more liberal standards for eligibility certification create more demand. VOTRAN has experienced a significant increase in the demand for ADA paratransit trips. Currently, through a strict application /certification process, VOTRAN determines that approximately 10 percent of those applying for ADA eligibility are able to use the regular fixed-route bus service. With implementation of conditional certification, VOTRAN should be able to better screen individuals who may be able to use fixedroute for some trips but may need paratransit for other trips. While some individuals may be unconditionally certified as ADA-eligible (meaning that there is no circumstance that enables the person to use fixed-route), other individuals may be certified as conditional, meaning that there are only some conditions that prohibit a person from using the fixed-route. Those conditions must be specifically enumerated. For instance, a person may only be able to use the door-to-door service when temperatures exceed 80 degrees, or on a return trip from dialysis. The goal will be to better manage the growth of demand for paratransit service.

\section{Maximize Fixed-Route Bus System Usage.}

VOTRAN has a mandatory bus pass program for Medicaid clients. This same program should be instituted for all Transportation Disadvantaged users within the fixed-route service area. If a TD trip has an origin and destination within the fixed-route service area, bus tickets or passes should be distributed to the user. If a Medicaid or TD trip is within the service area, every person must qualify under the strict application of ADA eligibility, in order to use paratransit. This will free up capacity on the paratransit system, provide greater independence to Medicaid and TD users, and reduce costs for both the transit system and TD program. 
5. Implement a Travel Training Program.

This training is to assist riders with the transition from paratransit to fixed route service, and is another useful tool to encourage more fixed-route usage under the TD program. Any opportunity that VOTRAN has to further educate its riders on the benefits of the fixed-route service should be taken. Most often, agencies are already in place that perform this service, such as the Center for Independent Living. It would be prudent for VOTRAN to coordinate with their existing services.

6. Provide Additional Training Opportunities for Contracted Operators.

VOTRAN provides limited customer service and safety training to contracted operator drivers but primarily depends on each of the operators to develop their own curriculum. VOTRAN provides a minimum of two weeks of classroom training and two weeks of on-the-job training for its Gold Service operators. This training focuses on customer service skills, sensitivity to persons with disabilities, and safety. Ideally, VOTRAN should implement similar training opportunities for those drivers of contracted operators to ensure that Gold Service users experience consistency and are comfortable with any driver.

7. Improve On-Time Performance Consistent With the System Service Standards.

It is often difficult to meet the on-time performance standard of 90 percent during the afternoon peak hours. It has been suggested that VOTRAN review the feasibility of implementing the use of a voucher system, using taxicabs to increase system capacity. 
8. Ensure the Availability of User-Friendly, Bilingual Transit Marketing Information.

VOTRAN should revisit the structure and format of its current route and schedule information, along with information applicable to ADA and TD users. Simplified, easy-to-use information in formats for bilingual and visually impaired individuals will benefit current and new users. It is further recommended that the system continue to ensure the availability of this information throughout the service area. For example, it would be beneficial to have information displays available at busier bus stops, major transfer points (i.e., all superstops), and any tourist-frequented locales.

VOTRAN should also continue to work with Volusia County to improve mapping tools that may be utilized to create more user-friendly and interactive maps and schedules on VOTRAN's website.

9. Continue the Vehicle Replacement Program and Purchase New Expansion Vehicles.

Fifteen paratransit vehicles are scheduled for replacement. The replacement vehicles will consist of 22-foot cutaways and 26-foot cutaways. No expansion vehicles are slated for purchase during this time, because it is assumed that any additional increase in demand for paratransit service that exceeds VOTRAN's supply will be accommodated by a recommended taxi voucher program and/or the brokering of the additionally required service to the existing private paratransit contractors. Nevertheless, it is important for VOTRAN to continue to do its best to accommodate paratransit demand through the use of its own paratransit fleet, as this facilitates increased multi-loading, thus reducing overall operating costs for paratransit. 
10. Continue to Encourage Public Input Through Interaction With Local Advisory/Advocacy Groups and Committees.

Public involvement should continue to be promoted. Transit systems with open channels for public input tend to be successful. VOTRAN has been proactive in making presentations and soliciting public input, as well as actively participating in the MPO's technical coordinating and citizen advisory committees. The system also regularly participates in meetings with the TDLCB, among other organizations, and has been lauded throughout the TDP process for the level of its public involvement.

11. Monitor all Technology Advancements Applicable to Public Transportation

As technology has continued to advance, transit increasingly has benefited from the availability of Advanced Public Transportation System (APTS) applications such as Automatic Vehicle Location (AVL), Geographic Information Systems, Automatic Passenger Counting, and magnetic fare cards, among other technologies. It would behoove VOTRAN to continue to monitor the ever-changing state-of-the-art in transit-related technologies for potential future application. It is possible that the planning and provision of service, as well as its inherent effectiveness and/or efficiency, can be enhanced through the utilization of some specific technology, or combination thereof. For the paratransit operations, particular attention should be given to AVL, scheduling software, and an advanced phone system. All contracted operators should be included in any and all technological improvements. 
12. Continue to Address the Mobility Needs of Volusia County Residents, Particularly Those in Transit-Dependent and/or Growth Areas, as is Financially Feasible.

The majority of the areas identified as being transit-dependent in nature are reasonably well served by the existing transit system, but VOTRAN should keep these areas in mind when considering improvements. In terms of mobility needs, these areas are extremely important. Any developing growth areas should be considered as VOTRAN continues to improve and/or expand its services.

13. Increase Span of Service on Selected Core Routes.

At present, VOTRAN's latest service ends at 7:47 p.m. (Route 1A). However, 94 percent of the system's users responding to the recent onboard survey expressed a desire for transit service that operates later into the evening. Nearly one-half of those respondents indicated that they would prefer the service to run until midnight. It is recommended that, initially, VOTRAN operate night service on its core Eastside routes (similar to those that operate on Sundays, and especially those that serve later evening destinations such as shopping malls and colleges), Monday through Saturday. It is expected that this later evening service will greatly improve access to and from colleges, malls, shopping centers, major businesses, hospitals, etc. Although somewhat limited geographically, this initial increase in span of service can be used to gauge interest in and utilization of the later evening service; it may even be possible to apply for a Service Development grant to help fund the additional service. Complementary paratransit service will be available for extended hours in the $3 / 4$ mile area surrounding the affected routes, for individuals who are certified as ADA-eligible. 
It is further recommended that, if utilization of the service warrants it and funding is available, the number of routes operating night service should be increased (i.e., at least a 50 percent increase in the existing late night service should be considered), again taking into account patron needs and later evening destinations.

14. Continue to Educate Customers on VOTRAN's Paratransit Service Policies.

VOTRAN should continue to seize opportunities to educate customers on service policies, such as pick-up window and no-show. VOTRAN's current pick-up window policy allows for a one-hour pick-up window for trips within the individual's community and a two-hour pick-up window for cross county trips. Trips are scheduled by the individual's appointment time. Often when a customer calls to schedule a trip, he or she assumes that the pick-up time will be based on his or her request. However, the actual pick-up time may be adjusted by the scheduling software based on the actual appointment time of the individual and the scheduling of other trips for that vehicle. While a passenger arrives at the appointment on time, he or she may argue that the vehicle was late based on the pick-up time requested. It is recommended that current practices to educate customers on this and other service procedures be continued. In addition, reservation clerks and customer service staff should also be prepared to explain and emphasize service standards to customers.

\section{Actions to be Initiated Within Two to Three Years}

15. Increase Frequency of Service in US 1 Corridor.

The US 1 Transportation Study identified a locally preferred transportation alternative that will improve mobility within the US 1 corridor while 
minimizing any impacts to neighborhoods and businesses in the study area. This alternative maintains the existing roadway configuration of US 1 and, among other improvements, is highlighted by a high emphasis on transit, bicycle, and pedestrian enhancements. It is envisioned that the planned improvements to the US 1 corridor will be phased in over the next 20 years. In fact, the MPO has adopted one of the recommendations of the report in the 2020 Long-Range Transportation Plan. Fifteen intersections from Park Avenue in Edgewater to Granada Boulevard in Ormond Beach are scheduled to improvements between 2006 and 2010. In addition, one of the transit-related improvements-the reduction of headways on the corridor's three "core" routes (Routes 3,4 , and 40) from 60 to 30 minutes-may be implemented during the time frame of this TDSP (FY 2004-2005). VOTRAN will need to ensure that it is actively involved in the implementation of all of the study's planned multi-modal improvements, especially those related to transit.

16. Implement Saturday Service on the Route 60 East-West Connector.

In order to connect the Saturday westside and eastside services, it is recommended that in FY 2004 the Route 60 Connector begin Saturday service with the same frequency and same span of service as weekday service. Complementary paratransit service will be offered along this corridor.

17. Revise Private Operator Contracts to Allow for Contract Amendments Based on Changes to Local Service Standards.

The contracts currently in place between VOTRAN and their contracted operators were originally established as three-year agreements with two one-year renewal options. During the final renewal period, the contracts should be revised to included language allowing for amendments based on 
changes to local service standards. The identification of specific standards in the current contracts has resulted in discrepancies between what is expected of VOTRAN related to levels and standards of service and how private operators are contractually obligated to perform. The service standards for the system were recently amended to increase the on-time performance standard from 85 percent to 90 percent. While some of the contractors are meeting and, in some cases, exceeding the standards established with their contract, some are not in compliance with the revised system service standards.

18. Revise Provider Contracts to Require All Newly Purchased Vehicles and Those Purchased After the Effective Date of the Contract to Have Standard Lifts with Transit-Style Doors.

Many of the vehicles currently being used by VOTRAN's contracted operators are conversion vans with lifts. The access doors for these vehicles are standard van doors that are smaller than those found on transit vehicles, making any maneuver more difficult and time consuming. It is recommended that the new provider contracts require that newly purchased vehicles or vehicles that are purchased after the effective date of the agreement have wheelchair lifts with transit vehicle access doors. It is expected that this change will assist operators in maintaining their schedules and meeting the 90 percent on-time performance standard. 
Table 8

Implementation Schedule

\begin{tabular}{|c|c|}
\hline Year & Improvement \\
\hline $2002 / 03$ & $\begin{array}{l}\text { 1. Pursue the establishment of a long-term dedicated funding source for } \\
\text { VOTRAN } \\
\text { 2. Continue to seek dedicated sources of funding to minimize the prioritization of } \\
\text { TD non-sponsored trips } \\
\text { 3. Use a strict certification process for ADA eligibility } \\
\text { 4. Maximize fixed-route bus system usage } \\
\text { 5. Implement a travel training program } \\
\text { 6. Provide additional training opportunities for contracted operators } \\
\text { 7. Improve on-time performance consistent with the system service standards } \\
\text { 8. Ensure the availability of user-friendly, bilingual transit marketing information } \\
\text { 9. Continue the vehicle replacement program and purchase new expansion } \\
\text { vehicles } \\
\text { 10. Continue to encourage public input through interaction with local advisory } \\
\text { and/or advocacy groups and committees. } \\
\text { 11. Monitor all technology advancements applicable to public transportation } \\
\text { 12. Continue to address the mobility needs of Volusia County residents, } \\
\text { particularly those in transit-dependent and/or growth areas, as is financially } \\
\text { feasible. } \\
\text { 13. Increase span of service on selected core routes. } \\
\text { 14. Continue to educate customers on VOTRAN's service policies. }\end{array}$ \\
\hline $\begin{array}{c}2003 / 04 \\
\text { to } \\
2004 / 05\end{array}$ & $\begin{array}{l}\text { 15. Increase frequency of service in US } 1 \text { corridor. } \\
\text { 16. Implement Saturday service on the Route } 60 \text { East-West Connector } \\
\text { 17. Revise private operator contracts to allow for contract amendments based on } \\
\text { changes to local service standards. } \\
\text { 18. Revise provider contracts to require all newly-purchased vehicles and those } \\
\text { purchased after the effective date of the contract to have standard lifts with } \\
\text { transit-style doors. }\end{array}$ \\
\hline
\end{tabular}




\section{Service Plan}

\section{Operations Element}

\section{Types of Service}

The Volusia County CTC coordinates ambulatory, non-ambulatory, and stretcher paratransit services, as well as fixed route bus service. Volusia County's paratransit service is administered under VOTRAN as a separate operating unit called "Gold Service." Gold Service is an advance reservation, door-to-door, non-emergency transportation system serving elderly persons, persons with disabilities, children at risk, and other transportation disadvantaged persons. Individual, group, and subscription service area also provided. Trip requests that exceed VOTRAN's capacity are contracted to private operators. Paratransit trips sponsored by social service or governmental agencies are provided on a countywide basis to agency clients.

Fixed-route service is available to the general public. Individuals living within $3 / 4$ mile of a fixed route who are unable to access or use the fixed route can apply for certification under the Americans with Disabilities Act of 1990 (ADA). This eligibility is for general purpose trips that are not subsidized by a governmental or social service agency.

Paratransit service for Medicaid non-emergency, medical appointments is scheduled through VOTRAN, where eligibility is verified and trips are authorized. Medicaid clients are also eligible for monthly fixed-route bus passes if they have at least two confirmed medical appointments in a month. The bus pass can be used to get to medical appointments and any other fixed-route trip purpose that the client wishes to make during the month. Medicaid clients who take advantage of the Medicaid bus pass program relinquish their paratransit rights. 
Social service agencies that have a need for client transportation may contract with VOTRAN to provide paratransit service. Rates are negotiated on an individual trip basis or hourly rates are available in the instance when agency clients can be grouped and taken to a common location. Agencies that are currently contracting with VOTRAN are:

Extended Family Services

Children's Home Society

Center for Visually Impaired

Division of Blind Services

Colonial Colony

Premier Rehabilitation

Vocational Rehabilitation
Aegis/ACT

Volusia County School Board

Work-Oriented Rehabilitation Center

Volusia County Health Department

Agency for Health Care Administration

Volusia County Council on Aging

MedWaiver Support Coordinators Program

\section{Days and Hours of Service}

VOTRAN's paratransit service is available throughout Volusia County beginning at 6:00 a.m. with the last pick-up at 6:00 p.m., Monday through Saturday. For those who are ADA-eligible, Sunday service is available between 6:00 a.m. and 6:00 p.m. in the Greater Daytona Beach area served by fixed-route bus.

Medicaid non-emergency transportation service is available seven days a week, 24 hours a day. After hours service is normally confined to nonemergency hospital releases. Out-of-service area trips are provided under Medicaid Monday through Friday only, with designated days for the most common destinations. 


\section{Accessing Services}

Individuals who qualify for any of VOTRAN's paratransit service can call to schedule a trip the day before and not more than two weeks in advance. Trip reservations are accepted Monday through Friday, 7:00 a.m. to 4:00 p.m. Same day trips are provided only in instances where special circumstances and capacities can accommodate requests.

VOTRAN's contract operators are on call after hours (6:00 p.m.- 6:00 a.m.) and weekends on a rotating basis to provide service for Medicaid clients. EVAC, the local ambulance service, handles calls after hours and refers all non-emergency Medicaid requests to the operator on duty. Telephones are forwarded to EVAC after VOTRAN offices are closed. Messages, such as next day cancellations, are taken by EVAC dispatchers and reported to VOTRAN the following morning.

Group trips are defined as those trips that are either picked up at one location and taken to one location or have a common origin or destination. Council on Aging diners are one example of group trips billed at an hourly rate, which is at a lower rate than individual trips.

Subscription trips are high user trips that occur on an established schedule, i.e., dialysis on Mondays, Wednesdays and Fridays. Once the customer's schedule is established, it is not necessary for them to schedule each trip, unless there is a cancellation or change to their schedule.

\section{Eligibility}

In order to be eligible for paratransit service, which includes ADA, Medicaid and TD-sponsored trips, an application must be completed. Part of the application includes a professional verification of the individual's disability or medical information that would qualify the person for door-to-door service. In 
instances where a determination is questionable, an independent company performs functional assessments. Persons potentially eligible for door-to-door service include elderly, disabled and children-at-risk. Persons sponsored by another agency, where the agency is purchasing service, may be certified as eligible to use paratransit service by that agency, and do not have to repeat the certification process with VOTRAN. Paratransit Patrons are re-certified every three years.

VOTRAN has a Medicaid bus pass program for those who have at least two verified medical appointments within a month and can use the regular bus service. VOTRAN certifies Medicaid recipients using the ADA model to determine eligibility for paratransit service. A significant number of Medicaid recipients are using the bus pass program, which has resulted in savings of several million dollars since implementation.

\section{Prioritization}

The Volusia County Local Coordinating Board has adopted the following trip priorities:
1. Medical
2. Work, Education, and Training
3. Food Shopping
4. Socialization and Recreation
5. Personal Business and Shopping
6. Other 


\section{Transportation Operators and Coordination Contractors}

Volusia County is a partial brokerage system, contracting with eight transportation operators for provision of service. VOTRAN also coordinates services with two non-profit agencies through coordination agreements. Table 9 lists operators currently under contract with VOTRAN.

Table 9

Contract Providers

\begin{tabular}{|l|c|c|c|}
\hline \multicolumn{1}{|c|}{ Name } & Contact Person & Service & Clients \\
\hline Trans Med & Dale King & A, W, S & All \\
\hline Transportation Services of Volusia County & Joe Meile & A, W. S & All \\
\hline Little Wagon & James Berry & A, W & All \\
\hline Florida Glider & Leon Bright & A, W & All \\
\hline Seminole Transit Service & Carlos Rivera & A, W & All \\
\hline MedOne Shuttle & Jimmy Jack & A, W. S & All \\
\hline Twinkle Star & Reginald Bryan & A & All \\
\hline Yellow Cab* & Frances King & A & All \\
\hline
\end{tabular}

* Cabs used on an incidental basis. There is no contract.

VOTRAN has a coordination agreement with Duvall Home, who is the Section 5310 operator in Volusia County. Duvall Home provides transportation for residential patients who have physical and mental disabilities. A coordination contract is also in place with Good Samaritan Inn, an ALF and Nursing Home, which provides all their own transportation. These services complement the coordinated system by providing economical transportation that meets the special needs of their clients, while increasing capacity on VOTRAN services. 


\section{Public Transit Utilization}

Medicaid clients who have at least two confirmed medical trips in a month and can use the fixed route are offered a monthly bus pass. The pass can be used for all their mobility needs, other than just medical appointments. The client has a $\$ 2.00$ co-pay and the remainder of the cost for the pass is billed to Medicaid. This win-win-win situation increases ridership on the fixed route, increases mobility for the client, and saves money for the Medicaid program.

\section{School Bus Utilization}

The School Board offers monthly VOTRAN bus passes for students who are eligible for school bus service. The intent is to use VOTRAN's existing capacity to cut back the expenses of operating school buses. VOTRAN provides some paratransit trips for the School Board to special needs students in isolated areas of the County. VOTRAN and the Volusia County School Board are designated by the Volusia County Emergency Management Services to coordinate evacuation for persons with special needs in the event of a disaster.

\section{Vehicle Inventory}

See Appendix B. 


\section{System Safety Program Plan Certification}

VOTRAN has an approved System Safety Program Plan (SSPP), in compliance with Chapter 14-90, Florida Administrative Code. (See Appendix $C$ for certification.) Private contract operators are also required to have an SSPP, and VOTRAN staff is responsible for monitoring contract compliance.

\section{Intercounty Services}

VOTRAN coordinates services with Flagler County Council on Aging (COA) for customers who live on the northern peninsula. On a daily basis, Flagler COA brings their customers into Volusia County for services. Some VOTRAN customers can be served more easily through this arrangement. VOTRAN also coordinates with LYNX A+ (paratransit service) to move Volusia County Medicaid clients in and around Orlando.

\section{Natural Disaster/Emergency Preparedness}

VOTRAN and the Volusia County School Board staff are designated by the Volusia County Emergency Management Services to coordinate evacuation for persons with special needs in the event of a disaster. The two entities have developed an arrangement where, in the case of an emergency, VOTRAN's paratransit telephone numbers are given to the public to call for assistance in evacuating the area. The paratransit unit then handles the physical evacuation of persons with special needs to safe shelters. The VOTRAN fixed route bus system continues to run its regular routes, while school buses are located at specific points along the routes. Individuals can board the school buses and proceed to be transported to shelters. 


\section{Marketing}

VOTRAN uses the professional resources of the Volusia County Public Information Office. Efforts have included the development and production of a "How-To-Ride" brochure, explaining all of VOTRAN's services, and promotional materials for the voluntary tag fee.

\section{Alternatives}

VOTRAN operates public transit service throughout Volusia County. It is a governmental entity managed by a private, for-profit corporation. This combination of public-private interests has proven successful in the provision of fixed-route and paratransit services. Since VOTRAN is providing generalized and specialized transportation, it is best to keep coordination under this umbrella. 


\section{QUALITY ASSURANCE}

\section{SERVICE StANDARDS}

Measures that exceed Commission standards are marked with an asterisk $\left(^{*}\right)$.

\section{Drug and Alcohol Testing}

The Volusia County CTC complies with applicable Federal Transit Administration and the U.S. Department of Transportation requirements for all those in safety-sensitive positions.

\section{Contract Monitoring*}

Contract compliance monitoring is performed quarterly by VOTRAN staff and consists of on-site visits. Monitoring of standards is done on a monthly basis using statistical reports generated by computer assisted scheduling program. Monthly performance reports are presented to the TDLCB.

\section{Driver/Vehicle Identification}

All VOTRAN drivers and drivers of contract operators are required to wear uniforms and picture identification badges. All vehicles are plainly marked with the name of the company in a prominent location.

\section{Local Toll-Free Numbers}

VOTRAN has signs posted in all paratransit vehicles with local toll free numbers to call for complaints and commendations. Customers may also use the toll free numbers to make reservations and to apply for service. The toll free numbers are also listed in the user guide along with how to file a grievance with the TDLCB and the TD Ombudsman hotline.

East Volusia: $\quad 386-322-5100$

West Volusia: $\quad 386-943-7050$

Southeast Volusia: $386-424-6810$ 


\section{Complaints*}

There should be no more than .85 complaints per 1,000 passenger boardings for VOTRAN Gold Service and 1.7 per 1,000 for private contracted operators.

\section{Seating}

All VOTRAN and Contractor vehicles provide seating based on the capacity of the vehicle. Each daily run has a vehicle assigned indicating seating capacity. VOTRAN's automated scheduling system assigns customers to runs based on the seating capacity of the vehicle. All VOTRAN vehicles are lift equipped to accommodate a mix of ambulatory and wheelchair customers for efficiency of multi-loading.

\section{Passenger Loading Assistance}

All VOTRAN and Contract Operator Drivers are trained in Passenger Assistance techniques. Training includes wheelchair/mobility assistance device loading, securement and storage, seat belt securement, door-to-door service, sensitivity awareness of persons with special needs and cultural diversity.

\section{Smoking, Eating and Drinking}

Signs are posted in all vehicles in the coordinated system prohibiting smoking, eating and drinking during transport. Drivers are not allowed to smoke, eat or drink on the vehicles.

\section{Passenger Property}

Passenger property that can be carried by the passenger and/or driver in one trip and can be safely stowed on the vehicle shall be allowed to be transported with the passenger at no additional charge. 


\section{Child Restraints}

Children under the age of four (4) years and/or under the weight of 45 pounds will be required to use a child restraint device. Due to cost of purchasing, maintaining and replacing the devices and for sanitary reasons related to transmittal of communicable diseases, the devices must be provided by the accompanying adult or escort.

\section{Escorts and Children}

Children under the age of six (6) and individuals requiring special assistance while en-route are required to have an escort. The escort must be able to provide the necessary assistance to the passenger and will be transported free. Only one escort may ride free of charge. A companion may ride for the applicable fare on a space available basis. A parent or guardian escorting an under age child may not bring additional children unless the other children have a scheduled reservation and will be receiving a service. In cases where it is not evident the individual needs an escort, medical documentation stating the reason an escort is needed will be required. Agencies who schedule under age children for services will be responsible for providing escorts or bus aides if a parent or guardian does not accompany the child.

\section{Passenger Trip Database}

VOTRAN maintains a database of all registered customers for the partial brokered program. All customers are certified eligible for service through VOTRAN and all customer information and service requests are maintained by the CTC. Contract operators are given daily manifest with customer names pick up and drop off times, location, and any other pertinent information such as wheelchair, walker, etc. 


\section{Pick-Up Window*}

Trips are scheduled by the individual's appointment time. There is a one- hour pick-up window for trips within the individual's community and a two-hour pickup window for cross county trips.

Scheduled return trips must be picked up at the time designated on the manifest. If a vehicle arrives earlier than the scheduled time on the manifest the driver must wait until the designated time. If the individual is not ready at the designated time, the trip may be placed on will call and the individual will be required to call in when they are ready to be picked up. Individuals placed on will call must be picked up within one hour from the time they call in. If an individual is not picked up within one hour it will be classified as a missed trip.

\section{On-Time Performance*}

A standard of $90 \%$ on-time performance has been established for all completed trips.

\section{Advance Reservations*}

Trips may be scheduled at a minimum of one day prior to date of travel and at a maximum of two weeks in advance, with the exception of subscription service. Same day requests are allowed only in instances of special circumstances and on a space available basis, with the exception of hospital releases, which require a minimum two-hour notice.

\section{Cancellations and No-Shows}

Individuals, their guardians or agency sponsor must cancel trips as soon as they become aware the trip will not be made. Trips must be cancelled no later than one hour prior to the scheduled pick-up time to avoid being classified as a no-show. Cancellations received less than one hour prior to pick-up time or at the person's door will be classified as a no-show. If the individual responds 
to any no-show notification and provides acceptable, verifiable evidence the no-show was due to an unforeseen, unavoidable circumstance or an error in scheduling, the missed trip will not be counted as a no-show.

For individuals who call in a day or more ahead to cancel trips, the trip(s) will be made inactive and not be classified as a cancellation. Same day cancellations, with the exception of less than one hour, will be classified as a cancellation. Up to six cancellations in one month will be allowed. Over six will be subject to the same progressive action as no-shows.

Persons who call in less than one hour to cancel a trip will be informed they will be charged with a no-show and informed of the penalty. On the first noshow occurrence, a letter will be sent by VOTRAN explaining the policy. If a third infraction occurs within 30 days, a letter will be sent by VOTRAN notifying the client they have been suspended from service for two weeks. When the individual is reinstated to the program, and they have three more no-shows within 30 days, the second suspension will be for 30 days. When the client is again reinstated and if three infractions occur within 30 days, the suspension will be 60 days. Upon the fourth occurrence, the individual's transportation privileges will be permanently terminated.

If an individual has a pick-up/return trip scheduled and is a no-show on the first trip, the return trip will not be cancelled unless the individual calls VOTRAN to cancel the return trip. If the return trip is not cancelled by the individual and is a no-show, it will be counted on the individual's record as two no-shows for the same day.

Individuals on subscription service (three times or more per week to the same location) must notify the VOTRAN office if they are not to be picked up. Three no-shows and/or six cancellations will result in loss of subscription privileges. 


\section{Driver Criminal Background Screening}

All drivers hired by VOTRAN are subject to a Florida Department of Law Enforcement (FDLE) criminal background check. Private operators are required by contract to adopt the same hiring policy.

\section{Training}

VOTRAN Drivers receive two weeks of intense training that includes defensive driving, driver safety, passenger sensitivity, wheelchair securement, and customer service. New drivers ride with an experienced driver for one week and an experienced driver rides with a new driver for one week before they are on their own.

VOTRAN and the TDLCB have elected not to require CPR and first aid training for drivers.

\section{Public Transit Ridership}

VOTRAN has a screening/certification and re-certification process to determine eligibility for use of the door-to-door service. Persons who are deemed ineligible for the door-to-door service are encouraged to use the fixed-route service. A goal of $15 \%$ referrals of paratransit applicants to fixed route service has been established.

\section{Accidents*}

VOTRAN has established a standard of no more than one preventable accident per 100,000 miles.

\section{Roadcalls*}

VOTRAN has established a standard of no more than one road call per 7,500 miles. 


\section{Call-Hold Time*}

All calls will be answered and will not be on hold more than three minutes. A standard of $90 \%$ of the calls completed has been established. This is monitored through a computerized automated call distribution system.

\section{Vehicle Cleanliness}

VOTRAN vehicles are cleaned and fueled and maintained daily. Contract Operators are required to keep their vehicles clean and follow prescribed maintenance programs. VOTRAN Road Supervisors randomly inspect Contractors vehicles for cleanliness. VOTRAN management inspects all Contractors vehicles and maintenance records on a yearly basis.

\section{Vehicle Heating/Air Conditioning}

All Vehicles in the coordinated system are required to have working heaters and air conditioners. In the event of a heater/air conditioner failure, the vehicle is taken out of service until repaired. VOTRAN vehicles are checked daily and contractor vehicles are spot checked by road supervisors. All contractor vehicles are inspected and heater/AC units are checked yearly.

\section{Two-Way Radio Communication}

All vehicles in the coordinated system have two-way communication systems. Base Stations are manned with dispatchers at all times to ensure constant communication with drivers. VOTRAN and Contract Operators have established radio policies and procedures. 


\section{Out-of-Service-Area Trips}

Out-of-Service Area trips are provided to Medicaid recipients only. Medical documentation is required to verify the service cannot be received locally. All trips out-of-area of more than 100 miles must be prior-approved by the District 4 Medicaid office. Trips other than to the Orlando area will be scheduled on Monday, Wednesday and Friday. Orlando area trips will be scheduled for one morning trip and one afternoon trip Monday through Friday. Individuals will be required to schedule medical trips on the days and times designated for purposes of multi-loading. Private contract operators will be paid only one mileage regardless of number of passengers.

\section{Service Interruptions*}

No more than one per 7,500 miles. An adequate number of spare vehicles must be available to continue service within 30 minutes in the event of an accident, breakdown, etc.

\section{Passenger Ride Time*}

Individuals will not be required to ride on a vehicle longer than one hour within local community and two hours cross-county. This excludes Medicaid out-ofcounty trips and Agency group trips.

\section{LOCAL GRIEVANCE PROCEDURE}

The adopted grievance procedure for Volusia County is found in Appendix D. 


\section{EVALUATION PROCEDURES}

\section{Community Transportation Coordinator}

Evaluation of the Volusia County CTC is conducted by the TDLCB, using the Evaluation Workbook of the Commission for the Transportation Disadvantaged.

\section{Operators and Coordination Contractors}

\section{Monitoring Procedures}

An initial inspection of contract operators will be made to determine if all compliance criteria is met prior to start of service. No contract operator will be allowed to start up service until all requirements are met.

Following start-up of service, quarterly monitoring inspections will be made to ensure ongoing compliance with requirements of the contract. Any deficiencies found during the inspections will be noted, along with corrective action necessary to correct the deficiencies. Time frames for corrective action are:

1. Minor deficiencies that do not affect safety or customer satisfaction with the service: 30 days.

2. Major deficiencies, such as safety issues, inability to meet schedules, drug testing requirements, etc., will result in a 10-day notification to correct problems. If deficiencies are not corrected within the 10-day period, the contract will be cancelled. 


\section{Evaluation}

1. VOTRAN staff will provide a copy of the quarterly monitoring reports to the Quality Assurance Committee of the TDLCB, along with corrective action needed.

2. An annual evaluation of the contract operators will be included as part of the CTC annual evaluation. An annual evaluation of the contracted operators will be conducted by VOTRAN staff and provided to the Committee for consideration.

3. The Committee will make recommendations to the CTC on improvements that need to be made or action on deficiencies that are not corrected. 


\section{Cost Revenue Allocation and Rate Structure}

\section{Cost Revenue Allocation}

The rate structure is the same for all Transportation Disadvantaged trips within Volusia County. Appendix E contains the Financial Plan from the recently-adopted Volusia County Transit Development Plan, along with the Cost Effectiveness and Efficiency worksheet from the most recent CTC evaluation.

\section{RATE Structure}

VOTRAN

Fixed Route Monthly Bus Pass

Ambulatory one-way

Wheelchair one-way

Hourly rate
$\$ 40.00$

$\$ 13.84$

$\$ 21.86$

$\$ 36.13$

\section{CONTRACTED OPERATORS}

Ambulatory one-way

Wheelchair one-way

Stretcher one-way

Out-of-area mileage

$\$ 16.19$

$\$ 24.21$

$\$ 59.85$

$\$ 1.70$ (plus $\$ 5$ boarding fee/person)

These rates have been approved by the Transportation Disadvantaged Local Coordinating Board (TDLCB) and the Florida Commission for the Transportation Disadvantaged (CTD) and were effective January 1, 2002. 


\section{TREND ANALYSIS}

\section{CTC TREND ANALYSIS}

A trend comparison was completed to compare the performance of the Volusia County CTC over time. The purpose of the analysis is to examine the performance of the CTC over the past five fiscal years. The trend comparison analyzed data for fiscal years 1997 through 2001. Table 10 shows the performance indicators and measures for each of the five fiscal years. This trend analysis represents a combined set of statistics for all TD transportation services coordinated through the CTC, including TD and Medicaid paratransit, fixed-route (unless otherwise specified), and subscription service.

Table 10

Trend Analysis for Volusia County CTC

\begin{tabular}{|l|c|c|c|c|c|c|}
\hline \multicolumn{1}{|c|}{ Indicator/Measure } & FY 1997 & FY 1998 & FY 1999 & FY 2000 & FY 2001 & $\begin{array}{c}\text { \% Change } \\
\text { (1997- } \\
\text { 2001) }\end{array}$ \\
\hline Total Passenger Trips & 534,257 & 597,626 & 594,322 & 602,505 & 635,908 & $+19.0 \%$ \\
\hline Total Vehicle Miles & $2,953,162$ & $2,670,734$ & $2,922,705$ & $3,101,797$ & $3,265,689$ & $+10.6 \%$ \\
\hline Total Revenue Miles & $2,737,967$ & $2,385,469$ & $2,456,056$ & $2,502,486$ & $2,808,900$ & $+2.6 \%$ \\
\hline $\begin{array}{l}\text { Potential TD Population } \\
\text { Transported }\end{array}$ & $3.7 \%$ & $3.4 \%$ & $3.8 \%$ & $3.7 \%$ & $3.9 \%$ & $+5.4 \%$ \\
\hline $\begin{array}{l}\text { Operating Expense per } \\
\text { Paratransit Passenger Trip }\end{array}$ & $\$ 13.84$ & $\$ 9.50$ & $\$ 11.93$ & $\$ 12.28$ & $\$ 13.21$ & $-4.6 \%$ \\
\hline $\begin{array}{l}\text { Accidents per 100,000 Vehicle } \\
\text { Miles }\end{array}$ & .61 & .79 & .79 & 1.42 & .18 & $-70.5 \%$ \\
\hline $\begin{array}{l}\text { Vehicle Miles between } \\
\text { Roadcalls }\end{array}$ & 33,182 & 47,692 & 69,588 & 79,533 & 51,836 & $+56.2 \%$ \\
\hline $\begin{array}{l}\text { Local Government Revenue } \\
\text { Ratio }\end{array}$ & $40.8 \%$ & $47.8 \%$ & $34.4 \%$ & $37.9 \%$ & $42.8 \%$ & $+4.9 \%$ \\
\hline
\end{tabular}

Sources: Florida Commission for the Transportation Disadvantaged: Annual Performance Reports, 1997-2001. 
The number of total trips has incrementally increased over the five-year period. Interestingly, total vehicle miles and total revenue miles saw a decrease between 1997 and 1998, and then began to show incremental increase, despite the increase in passenger trips. This is probably due to better multi-loading and/or better use of the fixed route.

The next two measures in Table 10 measure the cost efficiency of the services provided and coordinated by the CTC. Operating expense per paratransit passenger trip peaked in 1997, with a sudden drop in 1998. Again, this is most likely due to better use of the fixed route. The FY 2001 report indicates a 63-cent decrease in costs from FY 1997.

Quality of service and safety measures is also included in Table 10. Accidents per 100,000 vehicle miles are one measure of a transportation system's safety. There was a general downward trend (less accidents per vehicle mile) for this measure over the trend period. The quality of service measure that is included in Table 10 is vehicle miles between roadcalls (or service interruptions). The overall six-year trend for this measure is also positive, increasing more than $56 \%$ over the period.

Finally, the measure related to local government revenue collected within the coordinated system shows an overall increase for the five-year period of nearly $5 \%$.

These trends illustrate the performance of the CTC over a five-year trend period. Many factors and policies can affect these numbers; as such, they are presented for information purposes only. Explanation and critique should be conducted within the purview of the Local Coordinating Board. 